\title{
Factors Underpinning at Least Three Years of Participant Adherence to a Community-Focused Modified Boxing Program
}

\author{
Paul Perkins ${ }^{1,2,3}$, Allan Hahn ${ }^{1,4,5}$ \\ ${ }^{1}$ University of Canberra, Australian Capital Territory, Canberra, Australia \\ ${ }^{2}$ Ngunnawal Centre, University of Canberra, Australian Capital Territory, Canberra, Australia \\ ${ }^{3}$ Boxing Australia Limited, Canberra, Australia \\ ${ }^{4}$ Queensland Academy of Sport, Brisbane, Australia \\ ${ }^{5}$ Griffith University School of Engineering, Brisbane, Australia \\ Email: paul.perkins@uni.canberra.edu.au
}

How to cite this paper: Perkins, P. and Hahn, A. (2019) Factors Underpinning at Least Three Years of Participant Adherence to a Community-Focused Modified Boxing Program. Open Journal of Social Sciences, 7, 298-331.

https://doi.org/10.4236/jss.2019.72023

Received: January 30, 2019

Accepted: February 25, 2019

Published: February 28, 2019

Copyright $\odot 2019$ by author(s) and Scientific Research Publishing Inc. This work is licensed under the Creative Commons Attribution International License (CC BY 4.0).

http://creativecommons.org/licenses/by/4.0/

\section{Open Access}

\begin{abstract}
In Australia, a modified form of boxing aimed at maximising participant safety and enjoyment has existed since 2006. Known as Box’Tag, it precludes impacts to the head and neck, in accordance with recommendations of medical and other experts. It also makes use of automated scoring technology. From 2012-2016, a Box’Tag program was run at a Police Community Youth Club (PCYC) in Canberra, Australia, with the first author of this paper as the coach. It rapidly grew to include more than 100 regular participants, which was ten times the number involved in a conventional boxing program that it replaced. During its term, it gradually evolved to increasingly take on characteristics that seemed to be valued by participants. Upon its closure, participants were asked to complete a Program Evaluation Form as part of standard PCYC procedure. Among participants who met this request, there were 38 $(18 \mathrm{~F}, 20 \mathrm{M})$ who had been involved in the program for at least three years. We subsequently carried out thematic analysis of their written feedback to identify which aspects of the program had attracted them and were primarily responsible for their prolonged participation. Four major themes emerged, covering the program environment, the underlying concept, the timetable and the characteristics and outcomes of the training itself. Specifically, the environment was considered friendly, welcoming and supportive. The concept was seen to have extended beyond a sport program to encompass the establishment of a dynamic community brought together by a common interest. The program timetable was regarded as accommodating and flexible, and the training itself was described as safe, fun and beneficial in multiple respects. Overall, the participants expressed deep affection for the program.
\end{abstract}


Our findings accord with those of other researchers who have sought to discern factors influencing adherence to sport and exercise programs and who now suggest that traditional, highly instructional approaches to the operation of such programs might contribute to participant dropout. Prolonged involvement in the Canberra PCYC Box'Tag program is explicable in terms of self-determination theory, in that the program seems to have provided conditions that supported participant growth in autonomy, competence and relatedness. A strong case exists for replication of these conditions in other settings.

\section{Keywords}

Box'Tag, Community Sport, Modified Boxing, ModBox, Sport Design, Sport for all, Sport Participation, Self-Determination Theory

\section{Introduction}

Over the past five years, we have been part of a small team that has sought to determine whether it is possible to develop a modified, low-risk form of boxing capable of attracting large-scale community participation and involvement of population segments not well-reached by mainstream sports.

The first author of this paper has a background that makes him well-suited for such a project. He has been involved with boxing almost continuously since 1978, initially as an athlete and then as a coach. In the latter role, he has worked at all levels of the sport from novice to international and has received the highest level of accreditation offered by the International Boxing Association (the organisation which oversees the administration of world amateur boxing). In 2009, he was appointed to a position as a boxing coach at the Australian Institute of Sport (AIS) in Canberra. In this setting, he was exposed to the development of a modified form of boxing aimed at maximising the safety and enjoyment of participants.

Known as Box'Tag, the modified form was designed to add a new dimension to boxing by catering for people who were attracted by the fitness and skill aspects of the sport but who did not wish to take part in conventional boxing due to risk of injury [1]. The need for such a new dimension was suggested by low rates of participation in conventional boxing relative to community interest in the sport [2]. In keeping with recommendations from various medical and other experts [3]-[8], the rules of Box'Tag preclude impacts to the head or neck. Instead, the target zone is confined to the front of the torso and small areas on the upper arms. Even then, any impacts above a moderate level of force are prohibited, and as an additional safety measure, contestants are required to employ various items of protective equipment, including head guards and mouth guards. Scoring of Box'Tag contests is achieved through use of automated scoring technology that was initially developed by the AIS in conjunction with the Cooperative Research Centre for Microtechnology, and later improved through 
scientific and technical inputs from the Commonwealth Scientific and Industrial Research Organisation (CSIRO) and a small engineering company, Superinteractive Pty Ltd. [1] [2] [9]. The system is shown in Figure 1. It consists of specialised instrumented vests and boxing gloves incorporating sensor fabrics. The vests have thin stripes of silver nylon yarn that form a circuit when connected to a transceiver located in a pocket on the upper back. The transceiver directs a low-level electrical current through the circuit. Electrically conductive patches are positioned on the surfaces of the gloves. When a patch bridges two vest stripes, a change in the electrical resistance of the vest occurs and is detected by the transceiver, which sends the data by wireless mechanisms to a ringside computer. A customised algorithm is then applied to determine whether a score should be registered. Scores can be displayed in real time [10] [11]. The novel scoring technology has been regarded as one of the major attractions of Box'Tag [2] [9].

Toward the end of 2010, the AIS Boxing program was closed and the first author of this paper moved to a new position as Head Coach for Boxing at the Canberra Police Community Youth Club (PCYC). As a key aspect of the position he was required to substantially broaden participation in PCYC Boxing. $\mathrm{He}$ therefore decided to establish a Box'Tag program at the club. Exemplar programs already existed in Sydney and Melbourne, but were operating in commercial boxing and fitness centres. The introduction of Box'Tag at a not-for-profit, community-focused club similar to the one where the first author began his own boxing journey represented a unique challenge that he was keen to undertake.

The Canberra PCYC Box’Tag program was officially launched in January 2012 as a community engagement initiative. As it began to take shape, there was a realisation that it could provide a setting for research and development (R\&D) activities to support the ongoing refinement of Box'Tag-activities that previously had been performed largely in the context of the AIS Boxing program and the club hosting the Sydney Box'Tag program. After the successful completion of several small projects, a series of discussions between management of the Canberra PCYC and personnel from the University of Canberra resulted in the PCYC being formally recognised as a joint Field R\&D Centre of the two organisations (Figure 2).

The establishment of the R\&D Centre at the club coincided with progressive growth of the Box'Tag program to a point where it became the Canberra PCYC's most popular afternoon/evening activity, with over 100 regular participants-a 10-fold increase in participation compared to the conventional boxing program that it replaced. Many of the participants subsequently continued their engagement in the program for several years. It seemed important to understand the reasons for this high rate of uptake and adherence so as to provide a basis for successful implementation of similar programs elsewhere [12]. The present study was therefore undertaken in an attempt to identify which specific elements of the Canberra PCYC Box'Tag program were most influential in the attraction and retention of participants. 


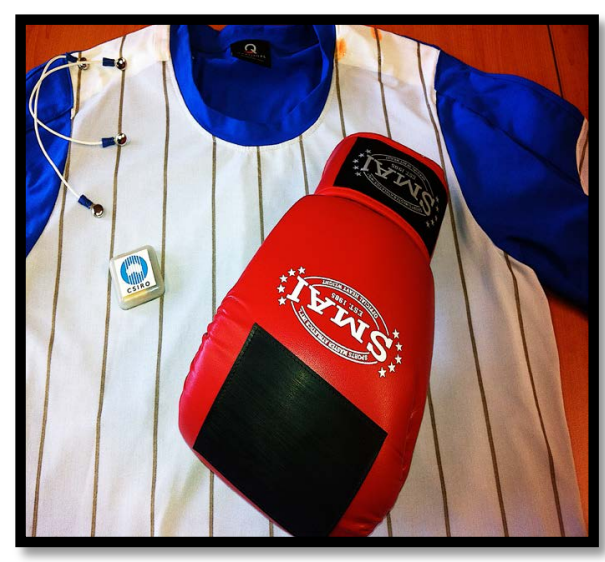

Figure 1. Components of the automated scoring system used in Box'Tag. The image shows an instrumented vest and a conductive patch on a glove. Wires connecting vest to transceiver also can be seen. When connected, the transceiver sits in a pocket on the upper back. Photograph provided by Kris Arnold Photography, Canberra, Australia.

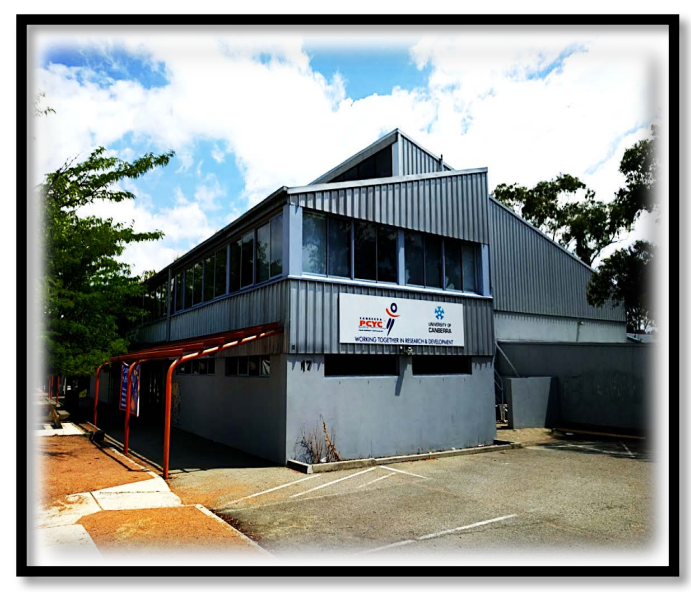

Figure 2. Outside view of the Canberra PCYC with one of three prominent signs displaying the partnership between the PCYC and the University of Canberra.

\section{Approach to Investigation}

We followed the examples of Bloor \& Macintosh [13], McLaughlin \& Ritchie [14] and Kirschbaum \& Knafl [15] by re-using existing data to tease out new understandings about a situation. Arguments in favour of this approach can be found in Hinds, Vogel \& Clarke-Steffen [16], Sandelowski [17], Szabo \& Strang [18], Thorne [19], Fielding [20] and Law [21]. These authors contend that secondary analysis of existing data can be used to generate new knowledge, new hypotheses, or support existing theories [16]; reduce the burden placed on respondents by negating the need to recruit further subjects [17]; provide an improved benefit/cost ratio for vulnerable groups who may be at risk from repeated data-gathering intrusions [19]; and allow for wider use of data from atypical or inaccessible respondents [20] [21].

In the context of the present study, a secondary analysis was made of data collected as part of normal operational procedures carried out by the Canberra 
PCYC to evaluate program effectiveness. The use of this approach was considered justified on the following three grounds:

\section{- Compatibility of the primary data with secondary analysis}

Thorn [19] notes that the "fit" between the purpose of the analysis and the nature and quality of the original data is an important factor when determining whether to use secondary analysis. As the data were originally collected for the purpose of program assessment, and this was the purpose also of the secondary analysis, a high level of compatibility exists.

\section{- Position of the secondary analyst}

Fielding [20] believes that the value of re-using qualitative data is maximised when extensive context is provided about the primary study. Silva [22] and Moore [23] also emphasise the importance of knowing the context of the fieldwork practices and note that without this knowledge, there is the potential for the data to be de-contextualised. The present study attempted to ensure that the context and meaning of the data were not lost by using the person originally responsible for the primary data collection to conduct the secondary analysis.

\section{- Ethical issues}

Growing interest in re-using data makes it imperative that researchers in general consider obtaining consent to cover the possibility of conducting secondary analysis [24]. This was the case for the participants in the Canberra PCYC Box'Tag program, all of whom signed consent forms granting permission for the collected data to be used in additional projects.

\subsection{Philosophical Assumptions}

The study was framed by an epistemological constructivist understanding that knowledge is socially co-constructed and generated from various perspectives [25], and guided by an ontological point-of-view that participants would construct different versions of the reality [26] that when analysed would create a detailed understanding of the experience [27].

\subsection{Ethical Approval}

Ethical approval for the study was obtained from the University of Canberra Human Research Ethics Committee and permission to re-use organisational data was provided by the Acting General Manager of Canberra PCYC.

\subsection{Data Generation}

Data for the present study were generated from the responses of 38 program participants (Table 1) who had at least 3 years of continuous involvement in the Box'Tag program and who had completed a final Program Evaluation Form upon closure of the program at the end of an almost 5-year term. The closure was due to restructuring of Canberra PCYC operational priorities and the appointment of the coach to a new position with another organisation.

The Program Evaluation Form consisted of three parts. The first was designed to obtain general demographic information. The second required participants to 
use a 5-point Likert scale to rate specific aspects of the program, including the extent to which it met their expectations, the suitability of the venue, the structure and format of training sessions, the exercises and activities employed, and the characteristics of the coach in terms of knowledge, methods and enthusiasm. The third part of the form posed eight open-ended questions, as follows:

1) Are the any additional exercises/training drills you would add to the program?

2) Were there enough training sessions?

3) Were the training times suitable?

4) As a result of participating in this modified form of boxing, would you be likely to compete in and/or train for conventional boxing?

5) Can you please describe the best features of the program?

6) Are there any aspects of the program that you think could have been improved, changed or deleted?

7) Has your participation in this program been beneficial? If yes, please explain how.

8) Can you please share your experience of the program?

Table 1. Details of the purposeful sample used to obtain varying first-hand accounts of the experience.

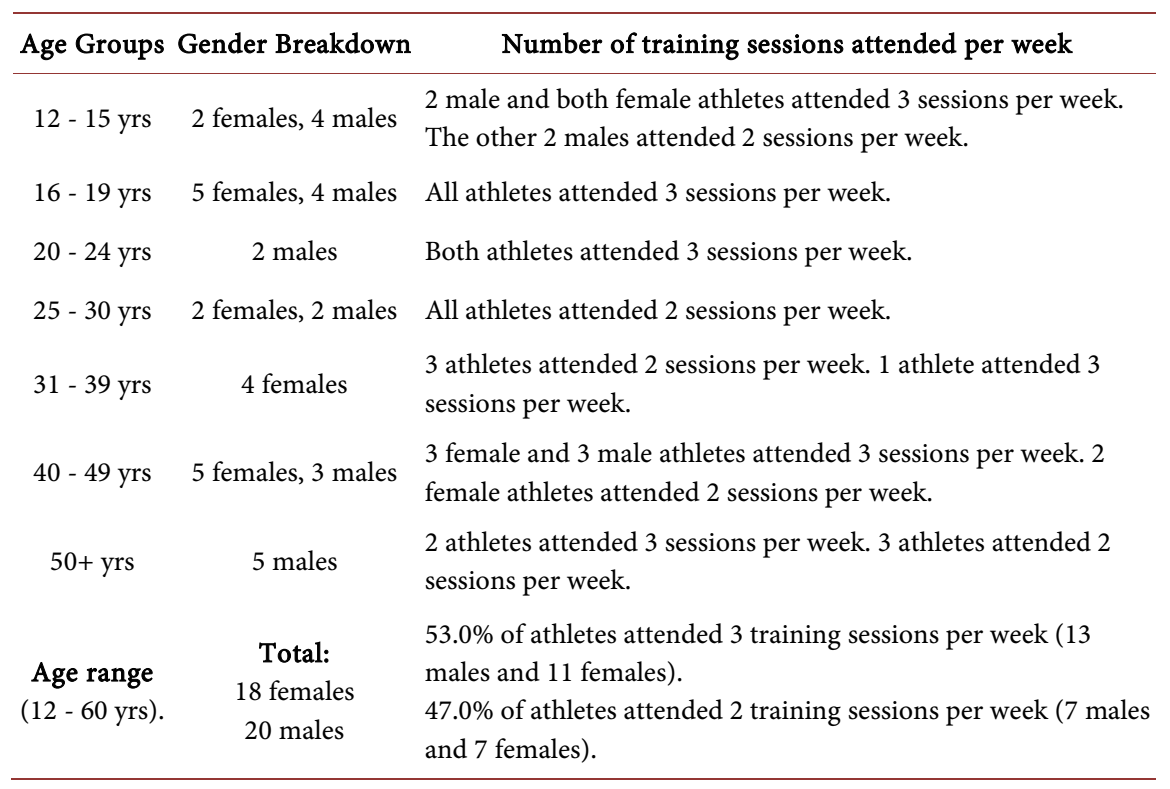

\subsection{Data Analysis}

In an attempt to ensure that the research objectives were met, responses from the evaluation forms underwent a 6-step analysis procedure (Table 2) that was consistent with the guidelines outlined by Braun \& Clarke [28] for the organisation, identification and interpretation of qualitative data.

\section{Results}

The analytical process outlined above revealed four major themes that together 
Table 2. The steps by which data were analysed. Following this process enabled interpretation of each individual account and the development of integrated themes.

\begin{tabular}{|c|c|c|}
\hline Steps & Purpose & Methods used in present study \\
\hline $\begin{array}{l}\text { 1. Become } \\
\text { familiar with the } \\
\text { data. }\end{array}$ & $\begin{array}{l}\text { Getting a sense of the } \\
\text { participants' experiences. }\end{array}$ & $\begin{array}{l}\text { Evaluation forms were rigorously explored one at a } \\
\text { time and notes were made to log early impressions. }\end{array}$ \\
\hline $\begin{array}{l}\text { 2. Generate } \\
\text { initial codes. }\end{array}$ & $\begin{array}{l}\text { Start organising the data in } \\
\text { a meaningful and } \\
\text { systematic way. }\end{array}$ & $\begin{array}{l}\text { Data were organised into small "chunks" of } \\
\text { information by highlighting any passage or word that } \\
\text { seemed relevant to the research question. This process } \\
\text { is known as open-coding. }\end{array}$ \\
\hline $\begin{array}{l}\text { 3. Search for } \\
\text { themes. }\end{array}$ & $\begin{array}{l}\text { Capturing the patterns in } \\
\text { the text that were specific } \\
\text { to the research question. }\end{array}$ & $\begin{array}{l}\text { Themes were initially developed by grouping the } \\
\text { related codes together based on their overall } \\
\text { significance to the research question and theoretical } \\
\text { similarities. }\end{array}$ \\
\hline $\begin{array}{l}\text { 4. Review } \\
\text { themes. }\end{array}$ & $\begin{array}{l}\text { Reviewing, modifying } \\
\text { and developing the } \\
\text { preliminary themes into } \\
\text { meaningful and authentic } \\
\text { units. }\end{array}$ & $\begin{array}{l}\text { This process involved combining some of the existing } \\
\text { themes and eliminating any that did not appear to fit } \\
\text { in with the emerging structure. The aim here was to } \\
\text { ensure that the themes accurately reflected what was } \\
\text { evident in the data and that when connected they } \\
\text { would provide a richer account of the overall } \\
\text { experience. }\end{array}$ \\
\hline $\begin{array}{l}\text { 5. Define } \\
\text { themes. }\end{array}$ & $\begin{array}{l}\text { Identifying the essence of } \\
\text { each theme-Braun \& } \\
\text { Clarke [28]. }\end{array}$ & $\begin{array}{l}\text { Consideration was given to the naming of each theme } \\
\text { so that an immediate indication of a particular theme's } \\
\text { essence could be clearly conveyed to the reader. }\end{array}$ \\
\hline 6. Writing up. & Reporting the findings. & $\begin{array}{l}\text { Words, extracts and comments from the original } \\
\text { evaluation forms were chosen to help illustrate and } \\
\text { exemplify elements of each theme. }\end{array}$ \\
\hline
\end{tabular}

summarised the participants' feedback. There was some overlap between the themes but Fielden et al. [29] have noted that this should be viewed as reflecting good interpretation rather than repetition as themes hardly ever emerge in isolation and are nearly always related to each other. The themes were as follows (with the figures subsequently shown in parentheses indicating the total number of participants who noted underpinning sub-themes):

- The environment: It was friendly, welcoming and supportive.

- The concept: It was more than a sport program-we were a community.

- The timetable: It was accommodating and flexible.

- The training: It was safe, fun and beneficial.

\subsection{Theme 1. The Environment: It Was Friendly, Welcoming and Supportive}

Stemming mostly from responses to Question 5 (Can you please describe the best features of the program?), the environment emerged as a significant factor for the participants' uptake of the Canberra PCYC Box'Tag program and sustained involvement with it. The environment was seen as a "positive" (19), "friendly" (24), and "supportive" (27) place that promoted "whole family participation" (14) and was always "welcoming" (21) and "encouraging" (17). Two pertinent and representative comments were as follows: "I have been to 
quite a few other gyms but have never seen a more family-friendly one or one that makes you feel so comfortable and welcomed. The place quickly becomes an extension of your life and going there used to be the highlight of my day"-(Female participant, 43 yrs old). "The success of this program was largely due to the charismatic way in which it was delivered. A positive, welcoming and supportive atmosphere encouraged repeated participation and made it easy to commit to on a weekly basis"-(Male participant, 51 yrs old).

For some participants ( 7 males and 11 females, aged 12 - 49 yrs), the training environment was a place where they felt "valued" (13) and "respected" (15) and where they were able to express themselves without fear of being "belittled" (11), "judged" (16) or "bullied" (7). These participants attributed this to the supportive nature of the environment, as can be seen from the following examples: “Knowing that I wasn't going to be ridiculed or bullied for not being good enough was one of the main reasons why I loved the program as much as I did and why I kept coming for as long as I did'-(Female participant, 16 yrs old). "One of the best things about the program was that nobody judged you if you couldn't do something very well. There was always someone willing to help and plenty of encouragement"-(Male participant, 14 yrs old). "Initially I felt very self-conscious about being in a training environment while I was overweight, and my lack of experience participating in a boxing-specific activity added to my insecurities. Within a relatively short amount of time, though, I stopped feeling self-conscious on both counts and was able to really enjoy the training. I believe this change was the result of regularly being in a positive, supportive and non-judgmental environment" -(Female participant, 46 yrs old). "Even though there was a wide range of ages and abilities at the training sessions everyone was considered important and given the same degree of commitment and enthusiasm and encouraged only through positive and supportive feedback rather than criticism"-(Female participant, 35 yrs old).

\subsection{Theme 2. The Concept: We Were More than a Sport Program-We Were a Community}

The emergence of the second theme suggests that one of the main aims of the program-encouragement of community engagement-was achieved. Fifteen females and fourteen males aged 13 - 60 years (and comprising 76\% of the study sample) spontaneously indicated that "a sense of community" was a contributing factor to their prolonged participation in the program.

The importance of "community" for the participants is clearly demonstrated in the following extracts: "I think the best feature of the program was the sense of community which was always welcoming and inviting"-(Male participant, $15 \mathrm{yrs}$ old). "I really enjoyed the sense of community at the program, and the welcoming nature of the coach and the other participants. Overall, I loved the whole experience and hope another program starts up soon"-(Female participant, 17 yrs old). "The program is built around people, from the coach through to the participants. It gave me the opportunity to become a part of a very special 
community and I have made a lot of good friends"-(Female participant, 37 yrs old). "The sense of community you got made the program really special. Everyone got on really well and we all tried to inspire each other to be the best that we could be"-(Male participant, 17 yrs old). "I enjoyed the training a lot, but for me it is was all about the people and being part of a special community that made it so appealing"-(Female participant, 33 yrs old). "Our whole family has been involved with and benefited from this program. We loved the community feel that you got as soon as you walked in the doors and the feeling of being a part of something really special'-(Female participant, 42 yrs old). "The participants were from a wide range of abilities and age groups making it a particularly family friendly environment and an effective community building activity" -(Male participant, 51 yrs old). "The nature of the program as well as the coach's style fostered a positive and supportive communitylteam culture"-(Female participant, 35 yrs old).

\subsection{Theme 3. The Timetable: It Was Accommodating and Flexible}

Participants who had to juggle work and family commitments with their commitment to training ( 8 males and 7 females, aged 25 - 53 yrs) made it clear from their responses to Questions 2 and 3 (Were there enough training sessions? and (Were the training times suitable?) that having different training sessions to choose from (Table 3) was "essential" (9) and "vital" (7) to their uptake of the program and sustained participation in it, as is evident from the following examples: "The program provided flexibility when necessary and I really appreciated the two time options that were available. I often had to work late, so having the later session meant I never missed out on training"-(Male participant, 53 yrs old). "The flexible training times and a variety of different sessions encouraged repeated participation and made it easy to commit"-(Male participant, 51 yrs old). "The training times and amount of sessions available were excellent. I primarily trained at the $6.30 \mathrm{pm}$ sessions on Monday, Wednesday and Thursday but on occasion, due to other commitments, I was able to train at the earlier time of $5.30 \mathrm{pm}$ and when needed I could also train on one of the other days"-(Female participant, 46 yrs old).

"I thought the overall of structure of the program and the variety of the training (technical and more fitness-orientated classes) was excellent. It was great back when I was able to do three sessions a week. However, since moving to the other side of Canberra I still managed to attend two sessions a week because of the amount of sessions that were available"-(Female participant, $28 \mathrm{yrs}$ old).

\subsection{Theme 4. The Training: It Was Safe, Fun and Beneficial}

There was a strong consensus amongst the participants ( 13 males and 16 females aged 13 - $60 \mathrm{yrs}$, constituting $76 \%$ of the study sample) that an emphasis on safety was an important feature of the program and a significant motivator for their involvement (see, for example, Figure 3). For instance, when responding to 
Table 3. An overview of the training structure that was considered by some study participants to be a contributing factor to their uptake and sustained involvement with the program. Examples of the different exercises, training drills and game-based activities used to develop and enhance the physical qualities and sport-specific skills of the participants can be accessed through a free online resource [30].



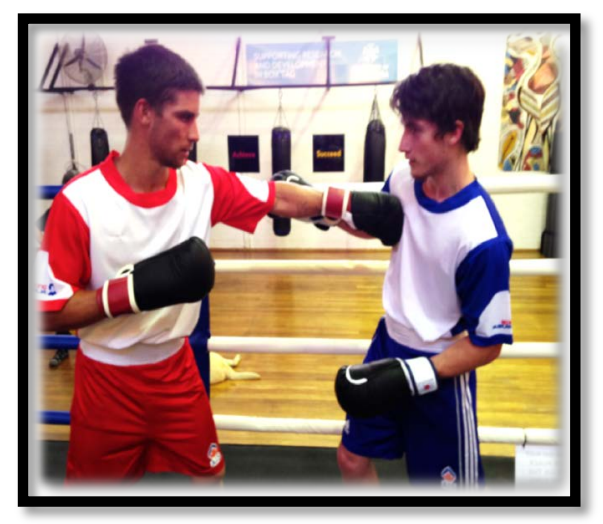

Figure 3. Two of the male study participants who identified a focus on safety as significant motivator for their involvement in the Box'Tag program. In this photo they are practising their sport-specific skills with specially constructed impact-damping boxing gloves that were developed by members of the research team as a means of improving participant safety and enjoyment. The gloves have been shown to significantly reduce peak impact forces [31]. Permission to use this image with the associated wording was provided by the people depicted.

Question 4 (As a result of participating in this modified form of boxing would you be likely to compete in and/or train for conventional boxing?) one of the male participants answered: "No! This program taught a much safer form of boxing in a very friendly and inclusive training environment that was available to people of all ages and levels of ability, which made it very unique and much more appealing than normal boxing"-(Male participant, 27 yrs old). Similar responses were provided by some of the other participants who compared their experiences with the Box'Tag program to previous experiences with conventional boxing: "The best feature of the program was the novel and safe approach to the training. It incorporated the latest in research by examining and developing new "better" ways of getting results. This prescient mentality and the focus on 
safety is what distinguished this program from the rest. The coach avoided the old school "macho" mentality, which is pervasive amongst the other established boxing gyms that I have trained in"-(Male participant, 28 yrs old).

"As a long-term martial artist with some prior boxing experience, I think our program was a way of emphasising the most beneficial and positive aspects of boxing (athleticism, technique and skil) while avoiding some of the aspects which tend to discourage broader participation (risk of head injury, overly aggressivel macho culture). This made the training not only very appealing but also very safe"-(Female participant, 35 yrs old).

The perceived importance of participating in a modified form of boxing that emphasised participant safety and enjoyment is also indicated by the following extracts: "I enjoyed the non-threatening atmosphere of this program as opposed to the boxing gym my friend and I tried before coming here. They weren't as friendly or as welcoming and the training was nowhere near as much fun or as safe"-(Female participant, 17 yrs old). "Having had a head injury in the past, I was very cautious about training again but after attending a few sessions here I quickly realised that Box' Tag is a really safe option and a great way to get fit and have a good time"-(Male participant, 28 yrs old).

"My parents don't like boxing - they think it is cruel and dangerous. That's the reason why my brother and I started training here"-(Male participant, 20 yrs old).

Having fun while training emerged as another factor that enhanced the participants' experience of the Canberra PCYC Box'Tag program. For some of the participants (9 males and 11 females, aged 12 - 60 yrs), having fun included training with friends. The participants used descriptions such as "it was the best, it made the training much more fun and enjoying" and "training with my besties was the coolest thing about the program" to express their feelings. Participating in game-based activities (see, for example, Figure 4) at the Tuesday and Thursday skill-specific training sessions was also highly regarded with 12 male and 14 female participants across all age groups indicating that this aspect of the training also contributed to their sustained involvement. For one of the younger participants the specially designed games were "heaps fun to do and a great way to get fit"-(Male participant, 13 yrs old), while one of the female participants thought this type of training was "a safe and fun way to learn the concepts of boxing while getting fitter and stronger"-(Female participant, 36 yrs old).

In addition to the above, a vast majority of the participants (17 males and 16 females across all age groups, amounting to $87 \%$ of the study sample) believed that the training was beneficial for accomplishment of personal, health and/or sport-specific outcomes (Figures 5-7), as exemplified by the following extracts: "The training was excellent. $\mathrm{P} m$ a lot fitter, stronger and more confident now and I really enjoy feeling this way"-(Female participant, 15 yrs old). "Every aspect of the training was excellent. The coordination drills were really challenging and required a lot of concentration. The boxing games enhanced my learning and skill levels and the conditioning training led to growth in strength, speed and endurance"-(Female participant, 34 yrs old). 
"I do the program as strength and conditioning training for rugby league and rugby union and my confidence, determination and skills have all improved as a result of my participation with this program"-(Male participant, 13 yrs old). "Watching my son grow and develop as a person as a result of his participation with the program has been a real highlight for me. Training here has taught him to be respectful and kind to others, to always do your best and the meaning of discipline and commitment" -(Male participant, 55 yrs old).

"This program has changed how I tackle physical activity. Prior to my involvement in this program I was tentative about what I was physically capable of and lacked the confidence to try. This program has increased my confidence in my ability to face physical challenges. I enjoy the challenge that each training session brings and, most importantly, I want to train"-(Female participant, 37 yrs old). "The sessions were always mentally and physically challenging, which produced a sense of accomplishment afterwards. I found the mindset I started to develop during the training sessions really beneficial and started to adopt a similar mindset to situations and environments outside of the program"-(Female participant, 46 yrs old).

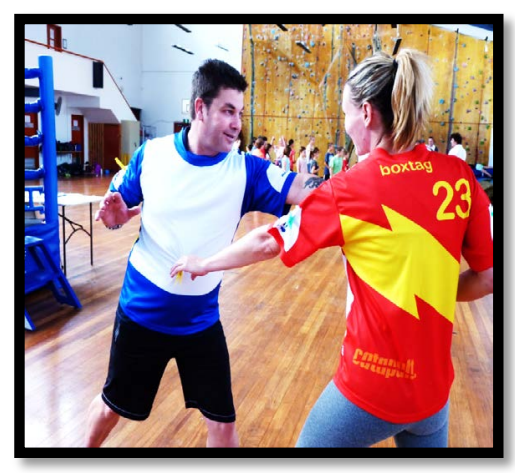

Figure 4. Participants playing a game called "peg boxing" at one of the program's skill-specific training sessions. In this activity, each partner attempts to snatch clothes pegs affixed to the other's vest. The game encourages development of tactical and movement skills resembling those required in Box'Tag. Permission to use this image with the associated wording was provided by the people depicted.

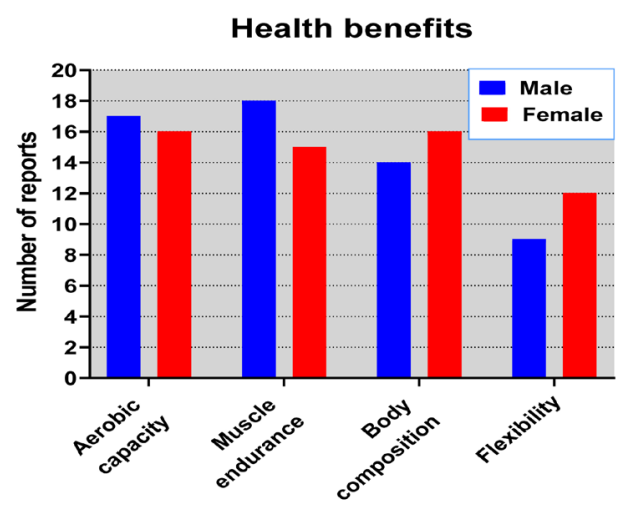

Figure 5. Number of study participants reporting specific health benefits that they attributed to their sustained involvement with the Canberra PCYC Box'Tag program. 
Personal skills

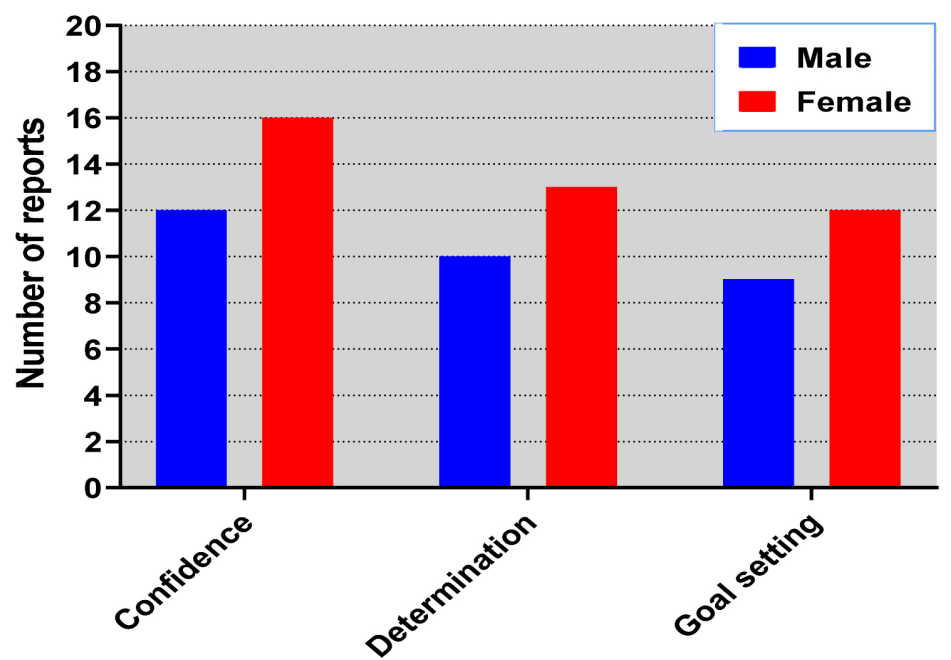

Figure 6. Number of study participants attributing improvement of specific personal attributes to their long-term participation in the Box'Tag program.

\section{Sports skills}

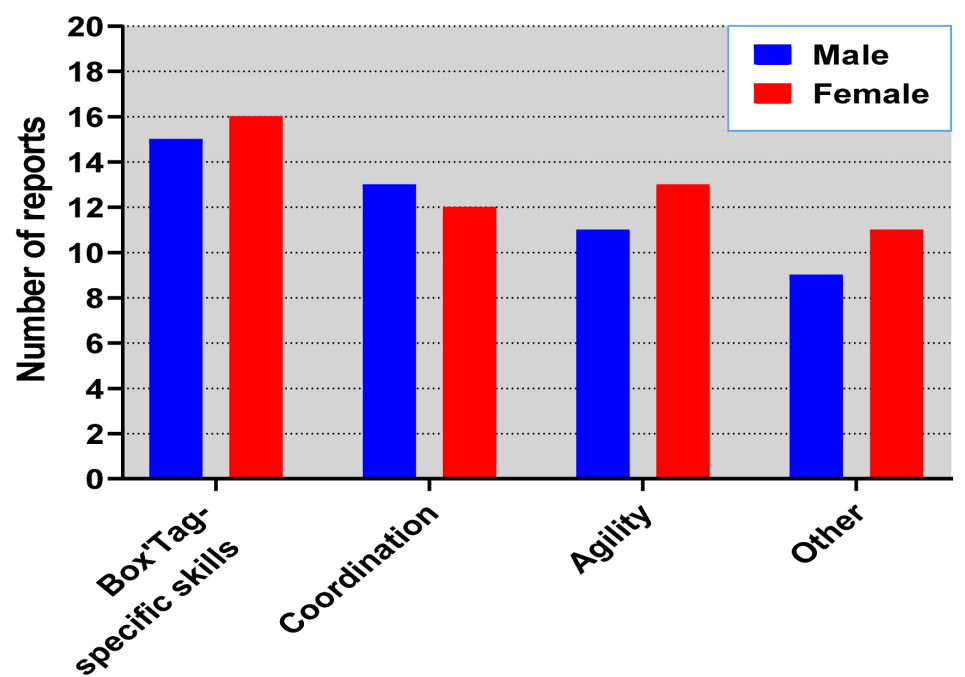

Figure 7. Number of study participants reporting improvement of specific sporting skills as a result of sustained participation in the Canberra PCYC Box'Tag program. Box'Tag-specific skills include footwork, movement patterns and attacking and defensive actions. The "Other" category includes weightlifting, running, jumping, skipping, throwing and catching.

\section{Discussion}

The present study set out to identify, interpret and report the key factors that encouraged participants to enroll in the Canberra PCYC Box'Tag program and maintain active involvement in it for at least three years. The results suggest that a perception of the training environment as friendly, welcoming, supportive and free of judgement was one such key factor.

This finding is consistent with the observations of other researchers. For ex- 
ample, a longitudinal investigation conducted by Casey et al. [32] showed that the participation of adolescent girls in sports clubs is influenced by their perceptions of the club environments. In the study [32], female students from 17 metropolitan and 14 non-metropolitan secondary schools in Australia took part in three annual surveys that recorded their current or past membership of sports clubs and the underlying motivations. For $\sim 80 \%$ of respondents, the friendliness of the club, knowing someone at the club and the friendliness of the coach were the predominant factors affecting their sport club participation.

The emergence of the first theme is also compatible with the literature on 'psychological safety' - the degree to which individuals feel comfortable taking positive interpersonal risks (such as trying something new) [33]. According to Edmondson \& Lei [34] and Merritt et al. [35], welcoming and supportive environments often promote a sense of psychological safety for participants by encouraging them to engage in authentic ways that align with personal motivations, which in turn, enables the co-construction of meaningful and productive experiences. When nurtured, these experiences can lead to participants feeling a sense of empowerment within their environments [33] [34] [35]. For example, research [33] [34] [35] [36] shows that when individuals feel a sense of psychological safety, they are more likely to demonstrate such self-regulated strategies as engaging in learning opportunities, admitting and learning from mistakes, providing feedback to others, sharing suggestions and helping others. It would appear that the environment at the Canberra PCYC was sufficiently positive, supportive, welcoming and non-judgmental to promote a feeling of psychological safety and a sense of empowerment for many of the participants, which in turn resulted in the development of some the self-regulated strategies described above and contributed to sustained participation in the program.

Participants in the present study made it clear that belonging to a special community was another key motivator for the longevity of their involvement in the Canberra PCYC Box'Tag program. This finding is consistent with research showing that people are more likely to stay involved in a community initiative when they feel they belong to that community, and when that community makes them feel valued and accepted [37] [38] [39]. This transfer of feelings and emotions is referred to as a Sense of Community (SoC) [40] [41] [42].

A number of scholars [40]-[45] have noted that sport is ideally positioned to promote, develop and enhance a SoC since it represents a social institution that offers a collective social experience for participants. In fact, it has been suggested that sport is one of the few remaining domains where this type of collective experience is promoted and experienced [43]. Warner and colleagues (Warner \& Dixon [44]; Warner, Dixon, \& Chalip [45]) used a grounded theory approach to examine the specific features that lead to a SoC among recreational and elite athletes in a collegiate sport context. Their research revealed that certain community features are required for development of SoC in such settings and yielded a seven-factor theoretical model outlining those requirements (Table 4). 
The emergence of an accommodating and flexible timetable as a theme demonstrates that the administrators of the Box'Tag program were at least partially successful in attempting to address one of the known barriers to sport participation by providing a range of options in relation to training times. In Australia, for example, it has been reported that many people find it difficult to be involved in organised sport because of the rigid structure of training and competition times and the resultant impact on family life [46]. This inflexibility has led to a significant shift toward less structured forms of exercise such as bushwalking, recreational cycling, gym training and park runs, and traditional sports are now in direct competition with these activities as vehicles for meeting the physical activity needs of the Australian public [46].

Research undertaken by the Australian Sports Commission (recently renamed as Sport Australia) in consultation with GfK Blue Moon provided an overview of challenges associated with Australian club-based sport participation. The research [47] was aimed at identifying motivators and barriers that influence decisions and behaviours of Australians in relation to club-level sport participation. Through use of a specifically developed needs-based, consumer-centric market segmentation model targeting sports participants and non-participants, the study concluded that club membership is being negatively influenced by the fact that Australians:

- Are increasingly time poor.

- Have limited budgets and are being inundated by new forms of entertainment.

- Have new preferences towards fun and fitness.

- Are increasingly favouring more flexible, non-organised forms of physical activity.

- Are developing new tastes as the population becomes more culturally diverse.

- Are sometimes self-conscious and embarrassed by their lack of sporting ability, with this applying especially to adolescents.

Further analysis of the results of the above study enabled grouping of identified barriers to adult sport participation into two categories-practical barriers and perceptual barriers (Table 5). The Canberra PCYC Box'Tag program was deliberately designed to address not only the issue concerning flexibility of training times but also many of the other issues, and the responses recorded by participants indicate that this was instrumental in their uptake of the program and their long-term adherence to it. For sport to keep pace with the changing needs of the public, there may be a need for the development and implementation of more community-focused programs based on contemporary knowledge of participation barriers.

The fourth and final theme that emerged from our analysis of feedback provided by participants in the Canberra PCYC Box'Tag program was focused on characteristics and effects of the training. It incorporated three sub-themes that are discussed below. 
Table 4. A summary of the seven mechanisms identified by Warner et al. [45] as contributors to a sense of community for participants within a sport setting.

\begin{tabular}{|c|c|}
\hline Factor & Definition \\
\hline Administrative consideration & $\begin{array}{l}\text { The level and intentionality of genuine care and concern expressed } \\
\text { by administrators for the safety and well-being of participants. }\end{array}$ \\
\hline Common interest & $\begin{array}{l}\text { Strong and positive group dynamics, social networks, and } \\
\text { meaningful friendship groups that form as a result of individuals } \\
\text { being brought together by a common interest. }\end{array}$ \\
\hline Competition & Opportunities to excel against both internal and external rivalries. \\
\hline $\begin{array}{l}\text { Equity of administrative } \\
\text { decisions }\end{array}$ & $\begin{array}{l}\text { Decisions and actions demonstrating that all members are treated } \\
\text { equally. }\end{array}$ \\
\hline Leadership opportunities & Opportunities to guide and direct others in the community. \\
\hline Social spaces & $\begin{array}{l}\text { A common area or facility in which athletes are able to interact } \\
\text { with one another. }\end{array}$ \\
\hline Voluntary action & $\begin{array}{l}\text { Self-fulfilling and self-determining activities resulting from little to } \\
\text { no external incentive. }\end{array}$ \\
\hline
\end{tabular}

Table 5. The practical and perceptual barriers to adult sport participation in Australia, as reported in the Australian Sport Commission Market Segmentation Report for Adults [47]. For many of the study participants, the overriding perception was that they were not the "type of participant" that would interest the clubs.

\begin{tabular}{ll}
\hline \multicolumn{1}{c}{ Practical barriers } & \multicolumn{1}{c}{ Perceptual barriers } \\
\hline $\begin{array}{l}\text { Lack of time, meaning other } \\
\text { commitments or interests took priority } \\
\text { over sport or physical activity. }\end{array}$ & A dislike of the assumed competitive nature of sport. \\
$\begin{array}{l}\text { A lack of information about how to get } \\
\text { involved. }\end{array}$ & Self-consciousness and a general dislike of certain sports. \\
$\begin{array}{l}\text { Costs-both purely financial and in } \\
\text { relation to perceptions of value for } \\
\text { money. }\end{array}$ & $\begin{array}{l}\text { Perception that club members are cliquey, exclusive, } \\
\text { single-minded and often highly judgmental of } \\
\text { non-participants or those with less ability. }\end{array}$ \\
$\begin{array}{l}\text { Location and convenience, including the } \\
\text { inflexibility of club schedules. }\end{array}$ & $\begin{array}{l}\text { Belief that sport clubs only operate an "open door" policy } \\
\text { feeling of lacking the level of skill needed to achieve } \\
\text { success. }\end{array}$ \\
$\begin{array}{l}\text { The commitment required as well as } \\
\text { other conflicting commitments. }\end{array}$ & $\begin{array}{l}\text { Lack of confidence in being able to break into the club } \\
\text { social scene, or inability/unwillingness to make the } \\
\text { required commitment. }\end{array}$ \\
$\begin{array}{l}\text { Club structures, "in-house politics" and } \\
\text { organisation. }\end{array}$ & $\begin{array}{l}\text { Belief that a highly competitive nature is a pre-requisite } \\
\text { for club participation. }\end{array}$ \\
\hline
\end{tabular}

The training was safe: The emergence of safety as a sub-theme is consistent with previous research undertaken by members of our team who performed an analytical interpretation of data collected from in-depth interviews of participants who had at least two years of involvement in the Canberra PCYC Box'Tag program [48]. Participants in that study (three females aged 27 - 44 yrs) considered "not being able to hit to the head", "using specially developed impact absorbing gloves" and "not intentionally harming anyone" as "vital" for their 
involvement with the program and noted that the risks involved with conventional boxing were "unnecessary", "inappropriate" and "completely avoidable".

There is unequivocal evidence that participation in conventional boxing entails serious risk of harm, including neurological damage [49] [50] [51] [52] and facial disfigurement [53]. Between 1990 and 2008, there were more than 37,000 presentations to United States Emergency Departments for head or neck injuries caused by boxing [54]. Boxing-related injuries were also responsible for a total of 437 British Army medical unit admissions from 1969 to 1980 [55]. Head trauma accounted for $\sim 68 \%$ of these injuries, but there were also 20 admissions for trunk injuries including rib and vertebral fractures, and 13 for kidney and pelvic organ injuries that required an average hospitalisation time of 6.2 days [55]. Medical studies have detected a relatively high incidence of electro-encephalographic (EEG) abnormalities and deficits in cognitive function amongst boxers [56] [57] [58] [59], and several studies have shown structural pathology in the brains of boxers including changes resembling those associated with Alzheimer's disease [60] [61] [62] [63]. Although the incidence of chronic traumatic brain injury is higher in professional than amateur boxing because of the longer duration of professional contests, magnetic resonance imaging reportedly shows discernible structural anomalies in the brains of $\sim 11 \%$ of amateur boxers [64]. Between 1890 and 2007, more than 1200 boxers, including 293 amateurs, died in the aftermath of contests [65].

The present study demonstrates that it is possible to modify rules, equipment and sub-culture to produce a form of boxing that is much safer while also able to attract and retain considerable numbers of participants. A notable finding of our research is that following its establishment the Canberra PCYC Box'Tag program rapidly drew a number of participants that was $\sim 10$ times greater than the level associated with a pre-existing conventional boxing program operating at the same venue. Even allowing for the fact that in general the Box'Tag participants trained less frequently and for slightly less time per session than the conventional boxers, overall use of the training venue had an approximate four-fold increase. It is also salient that the Box'Tag program attracted participants from outside the conventional boxing community, with its perceived safety being crucial in this regard, as summarised by one of the older male participants who wrote: "The whole concept of this program is to encourage participation in a safer form of boxing, learn new skills and create a sense of community. This is a program that should be greatly encouraged because it works and it is needed. However, it should not lose its prime objective of a community experience that is available to everyone"-(Male participant, $60 \mathrm{yrs}$ ).

Nevertheless, uncertainty remains concerning the extent to which modifications such as those introduced at the Canberra PCYC would ever be accepted by the wider boxing community [66], since it is believed that the cultural, visual and emotional appeal of the sport to that community is closely tied to the inherent risks [67]. A primary effect of the modifications may be an ability to substantial- 
ly broaden the historical boxing demographic.

The training was fun: For the participants in the present study having fun while training was perceived as "essential" to their sustained involvement in the Box'Tag program, with 29 of the 38 survey respondents spontaneously mentioning this aspect (see, for example, Figure 8).

This finding is consistent with literature showing that two sources of fun are important for achieving long-term sport participation [68].

1) Situational influences such as positive and meaningful social interactions [69]; supportive relationships [70]; the challenges involved with learning the activities and training drills [71]; and extrinsic rewards such as praise from coaches and peers [72].

2) Individual characteristics including high perceptions of sporting competence [72] and achievement of high skill level [73].

Interestingly, it appears that the perception of fun depends less on winning than on simply performing well and achieving a desired outcome when there is something at stake [74].

In the present context, the participant perceptions of fun consisted mostly of training with friends (a situational influence) and the use of constrained games [75] [76] for the development of sport-specific skills (a situational and individual characteristic).

The use of the constrained games at the program enabled participants to develop their tactical appreciations of Box'Tag and acquire the skills necessary for displays of competency by providing them with opportunities to explore and

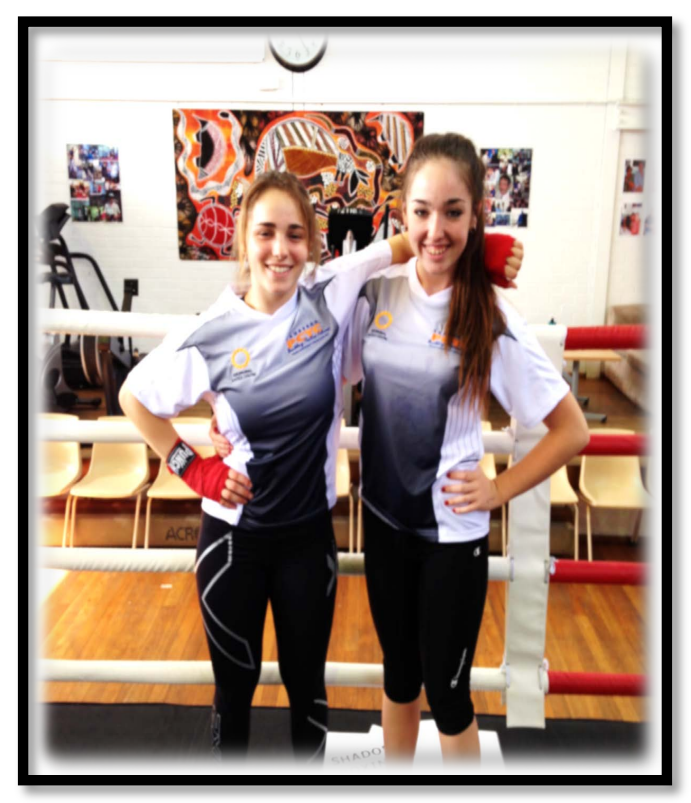

Figure 8. Two of the younger female study participants who considered training with friends and the achievement of high skill levels through use of novel, constrained games as a lot of "fun" and important motivators for their sustained involvement in the Canberra PCYC Box'Tag program. Permission to use this image with the associated wording was provided by the people depicted. 
discuss the tactical aspects of the activities [77] [78] in an encouraging, supportive, inclusive and non-judgmental training/learning environment. This approach to skill development is in stark contrast to the more traditional and highly structured "skill-drill" methods that focus on the individual technical elements of a sport separate from the context in which they are to be applied, and generally prior to any actual participation [79] [80] [81]. The latter methods provide little scope for the development of tactical knowledge [82] and are contradictive of the specificity of motor learning and the fundamental principles of skill transfer [83].

Learning and development of skills are seen as essential elements of sports participation [72], and our data suggest that encouraging friends to train together while developing their skills through the use of constrained games enhanced the participants' experience and contributed to their sustained program engagement.

The training was beneficial: Another important finding of our research was that 33 of the 38 athletes who completed the Program Evaluation Form suggested that participation in the Canberra PCYC Box'Tag program was beneficial to development of health, personal and/or broader sporting outcomes (see, for example, Figure 9).

A perception that the training was beneficial for improving the physical qualities of participants is not surprising considering the length of time they spent with the program and available data suggesting that boxing training is an excellent activity for the development of physical fitness [84]. National male amateur boxing squads from England, France and Germany have recorded average maximum oxygen uptakes in the vicinity of $60-65 \mathrm{ml} \cdot \mathrm{kg} \cdot \mathrm{min}^{-1}$ [85] [86], which far exceeds the 42 - $46 \mathrm{ml} \cdot \mathrm{kg} \cdot \mathrm{min}^{-1}$ considered "good" for 20 - 29 year old males [87]. Results from a study that investigated the punch forces of senior male English

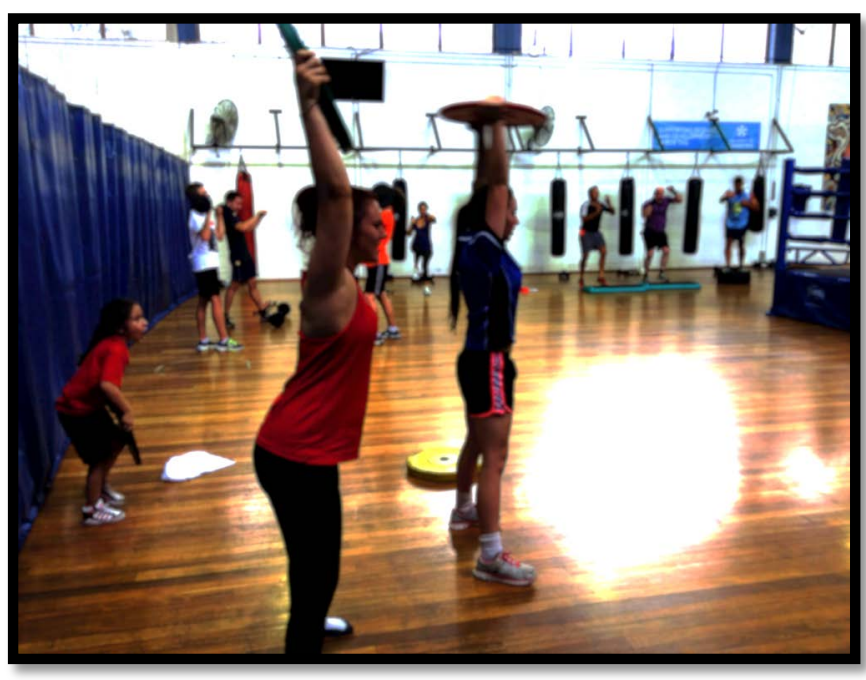

Figure 9. Some of the study participants taking part in a strength and conditioning training session that formed part of the Box'Tag program. Permission to use this image with the associated wording was provided by the people depicted. 
amateur boxers also helps to demonstrate the effectiveness of boxing training [88]. The study was conducted in a laboratory situation and revealed punch forces reflecting extraordinary neuromuscular capability [88].

Boxing training is also a highly efficient way to exercise. This is evident from a study that compared the energy expenditure of boxing-specific training with treadmill running [89]. Eight adult males with experience in boxing training completed the following three sessions:

1) A one-hour boxing-specific workout in a laboratory.

2) A one-hour boxing-specific workout in a gym.

3) A one-hour incremental run on a treadmill.

The subjects were found to have an average energy expenditure of 671 calories (2807 kilojoules) in the laboratory and 599 calories (2506 kilojoules) in the gym when performing the boxing training. To achieve similar energy expenditure on the treadmill, the participants had to run approximately $9 \mathrm{~km}$ during the one-hour session. The researchers considered the energy expenditure high for all three tests but concluded that the boxing workouts were more anaerobic and required greater overall body power than the treadmill running [89].

Participant perceptions that involvement with the Box'Tag program was beneficial for the development of a number of personal attributes may be a reflection of their long-term program engagement, since it has been reported that prolonged sport adherence is crucial not just for the development of sporting skills, but also for the changing of attitudes and behaviour as a consequence of sports experience [90]. There is considerable debate, however, as to whether sports participation in general has any character-building effects, and instances of athletes using prohibited performance-enhancing drugs, cheating, abusing officials and committing crimes outside of the sporting arena are sometimes cited as evidence to the contrary [91]. Current expert opinion is that sport does not inherently build character but can do so if the experience is structured in a way that places an imperative on specific behaviours, provides appropriate role models and rewards demonstration of positive behavioural traits [92] [93]. In the context of the Canberra PCYC Box'Tag program, a focus on "whole-person" development (rather than just athletic development) by encouraging, modelling and rewarding such desirable values as fair play, cooperation, responsibility, determination, empathy and continuous learning appears to have been recognised and favourably regarded by participants and to have contributed significantly to their lasting involvement (see, for example, Figure 10).

Participants indicated that their long-term engagement with the Canberra PCYC Box'Tag program was also motivated by their perceived development of Box'Tag-specific skills, as well as a range of other more fundamental movement and physical literacy skills such as coordination, agility, skipping, hopping, jumping, throwing and catching (see, for example, Figure 11).

The emergence of this sub-theme is consistent with the literature on exercise motivation from the perspective of self-determination theorists [94] [95], who 


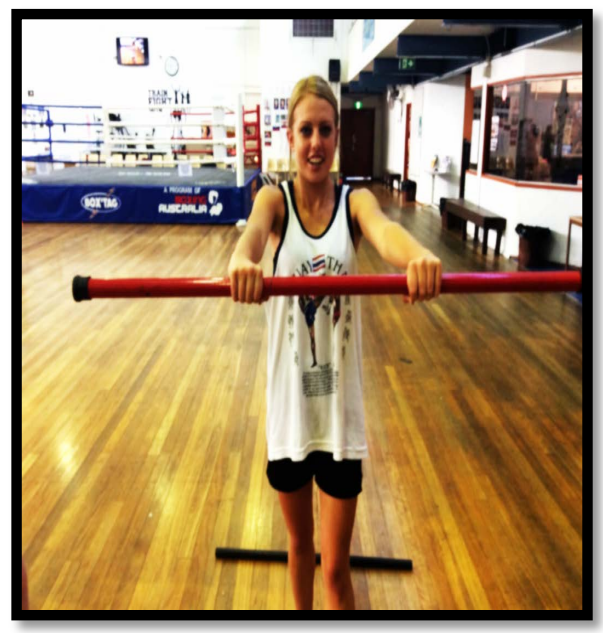

Figure 10. A young female study participant who reported that her long-term involvement in the Box'Tag program was responsible for the development of important personal attributes such as determination, goal setting, leadership skills, and improved self-confidence and self-image. Permission to use this image with the associated wording was provided by the person depicted.



Figure 11. One of the older male study participants who indicated that his long-term involvement in the program was motivated by his development of Box'Tag-specific and other more general fundamental movement and physical literacy skills. This participant was blind, which demonstrates the importance of maintaining a "sport-for-all" concept so that people of all ages can enjoy the social, health and personal benefits associated with sport participation regardless of their gender, cultural background or levels of functionality. Permission to use this image with the associated wording was provided by the person depicted.

contend that a lack of motivation toward sport and/or exercise can be broadly explained by two factors.

Firstly, some people do not wish to participate in sport due to competing demands on their time (from such external sources as school/education commitments, family interests and career obligations), or do not place enough value on the outcomes potentially achievable through such participation to justify making 
sport and/or regular exercise a priority in their lives [95] [96]. The second factor is that some people perceive that they are not physically fit or skilled enough to take part in a sporting or recreational activity of their choice, which in turn, presents a significant barrier to participation [95] [97]. These factors are among those reported also by the Australian Sports Commission [47], as presented earlier in this paper.

It has been reported that some individuals express high levels of personal motivation to exercise regularly and/or commit to a sporting program, but then go on to display behaviours to the contrary, reflecting little follow-through and a lack of genuine commitment [98] [99]. Of particular concern is that a significant number of people exercise or participate in sport only because of such externally controlled motivations as improving appearance or gaining a positive reward. For example, participation in recreational activities like going to the gym or running regularly is often based on a feeling of "this is something I have to do" rather than "this is something I truly want to do" [100] [101].

The above highlights that many individuals are either unmotivated or not sufficiently motivated to be physically active or are motivated by externally-driven considerations that generally do not lead to sustained participation. This demonstrates a need for further investigation of the self-regulatory factors associated with regular sport participation and other forms of physical activity [100]. Based on self-determination theory [94] [95] [96] [97], it has been argued that the stability of an individual's motivation is partially dependent on the degree of perceived autonomy. The implication is that self-endorsement for an activity and a willingness to improve that is driven by self-approval should result in greater levels of persistence and longer involvement [100] [101]. This suggests that the use of utilitarian approaches and over-prescriptive instructional coaching methods to promote exercise and sport participation, as often prevalent in group exercise classes and sport settings where exercises and training drills are externally prescribed, could actually be partially responsible for the high dropout rates observed in such settings, and accordingly could be ill-suited for the promotion of sustained sport participation [101] [102] [103] [104].

The Canberra PCYC Box'Tag program provided its members with an autonomy-supportive training environment in which their participation was voluntary, their opinions were valued and sharing of their ideas was encouraged. This may have fostered high levels of self-endorsement for the various training activities and led to involvement in the program being mostly self-driven by a desire and willingness to improve, with such intrinsic motivation externally reinforced by a program philosophy of continuous learning. It seems likely that resultant feelings of satisfaction contributed to the prolonged engagement of the participants with the program, which in turn provided the time necessary for the development of sport-specific and other more fundamental movement and physical literacy skills, and for formation and consolidation of social relationships. The program environment therefore may have supported participant expe- 
riences of autonomy, competence and relatedness. Self-determination theory suggests that conditions providing for meeting of these basic psychological needs are associated not only with persistence, but also with enhanced performance and creativity [97] [98] [99] [100] [101]. Perceptions of competence and relatedness were very clearly communicated in the written feedback from Canberra PCYC Box’Tag program participants.

An interesting and somewhat surprising finding arising from the present study is that the participants made no mention of the automated scoring technology, which up to now has often been considered one of the major attractions of Box'Tag and an integral part of the concept [2] [9] [105]. The lack of mention occurred even though the program participants had regular exposure to the technology, which for a considerable period was made available weekly for use in Box'Tag sparring. Although the nature of the present study precludes formation of definitive conclusions as to why access to the scoring technology was less highly regarded than other program characteristics, the finding suggests that most members of the Canberra PCYC Box'Tag program were choosing to participate for reasons other than competing. This suggestion is compatible with the AusPlay participation data collected by the Australian Sports Commission between October 2015 and September 2016 [46]. The data show that only 5\% of $\sim 20,000$ survey respondents aged 15 yrs and older identified competition as the key motivator for their participation. In contrast, the top three motivators for sport participation during the above period were:

1) Improving physical health and/or fitness (63\%).

2) Having fun (55\%).

3) Gaining social benefits (32\%).

The automated scoring technology has been a key component of the Sydney Box'Tag program, which has operated since 2006, staging regular Box'Tag competitions for its members. Conducted similar to conventional boxing tournaments, these events provide an opportunity for club participants to demonstrate their skill levels, and to experience the thrill of competition in encouraging and supportive environments.

We have assisted with setting up and running the technology at the Sydney events and have seen at first hand that the objectivity of the scoring and the excitement generated by dynamic, real-time display of scores (Figure 12) is almost always favourably received by participants and audiences alike.

Given that there appears to be more of a desire for the scoring technology at the Sydney club, a case could be made for the development of two different forms of modified boxing, especially since the Sydney program is more geared toward preparing athletes for traditional boxing and sometimes uses Box'Tag as an entry-point to help prepare athletes for formal competition within the amateur boxing ranks. Promoting at least two different forms of modified boxing has the potential to enable greater uptake of the modified boxing concept by aligning individual motivational characteristics to additional participation opportunities, 


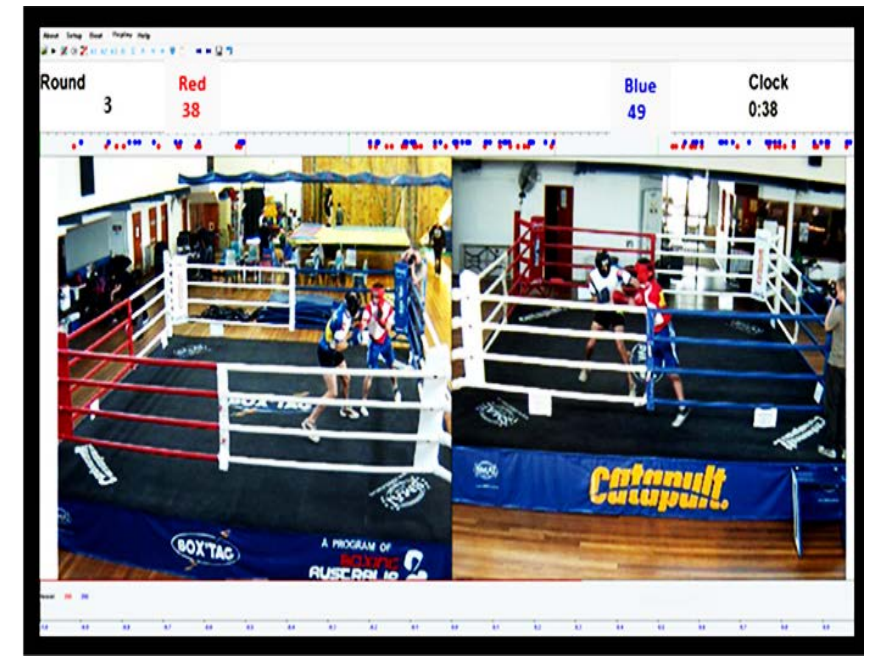

Figure 12. Real-time displays of scores in a Box'Tag contest through the use of the automated scoring technology.

which in turn would increase the possibility of greater community engagement. For example, Bailey et al. [106] propose that involvement with sport occurs for a number of reasons and, in keeping with the findings derived from the AusPlay participation data of the Australian Sports Commission [46], they note that for many people competing and/or winning is not a significant motivator for their participation. Instead, Bailey et al. [106] contend that there are three different categories of sport participation, which are summarised in Table 6. Also included in Table 6 are suggestions as to how these categories could be developed into a modified boxing implementation framework, designed specifically to be compatible with the views of Collins [107], who described sport development as "a process of effective opportunities, systems and structures that are set up to enable people in all or particular groups and areas to take part in sport and recreation or to improve their performance to whatever level they desire".

To differentiate modified boxing programs with a predominant sport-for-development focus from those placing greater emphasis on competition between athletes, introduction of distinct program names might be helpful. Accordingly, we have begun to refer to programs resembling that which evolved at the Canberra PCYC as "ModBox", while continuing to call programs modelled on the one at the Sydney club Box'Tag. Over the past two years, with support from the Australian Department of Foreign Affairs and Trade, ModBox programs have been implemented as a sport-for-development initiative at 16 schools and a substance abuse rehabilitation centre in northern India. An overview of that initiative is available in a free online document [108].

Apart from the automated scoring technology, several other aspects of the Canberra PCYC Box'Tag program that we had thought attractive to participants elicited little or no comment on the Program Evaluation Forms. Included here was the positioning of the Canberra PCYC as a Field R\&D Centre through which the participants effectively became co-developers of the Box'Tag program and 
Table 6. A summary of the different categories of sport participation as reported by Bailey et al. [106] and their possible applications to establishment of a modified boxing implementation framework incorporating modified boxing programs with different primary emphases.

\begin{tabular}{|c|c|c|}
\hline $\begin{array}{l}\text { Categories of sport } \\
\text { participation }\end{array}$ & Definition & Most suitable program \\
\hline $\begin{array}{l}\text { Participation for } \\
\text { Personal Wellbeing } \\
\text { (PPW) }\end{array}$ & $\begin{array}{l}\text { Participants take part in } \\
\text { sport for personal wellbeing } \\
\text { reasons including the social } \\
\text { and health benefits } \\
\text { associated with participation. }\end{array}$ & $\begin{array}{l}\text { A sport-for-development initiative modelled } \\
\text { on the Canberra PCYC program would aim } \\
\text { to use sport as a vehicle to assist the positive } \\
\text { growth and development of the participants } \\
\text { and to help build happier and healthier } \\
\text { communities. }\end{array}$ \\
\hline $\begin{array}{l}\text { Personally Referenced } \\
\text { Excellence } \\
\text { (PRE) }\end{array}$ & $\begin{array}{l}\text { Participants gain enjoyment } \\
\text { from skill development and } \\
\text { the challenge of surpassing } \\
\text { their previous performances. }\end{array}$ & $\begin{array}{l}\text { The above sport-for-development initiative } \\
\text { and the existing Box'Tag program operating } \\
\text { at the Sydney club would both be suitable } \\
\text { for this category of sport participation, since } \\
\text { participants within this category tend to } \\
\text { gain enjoyment from learning skills and the } \\
\text { challenge associated with bettering their } \\
\text { previous best efforts. }\end{array}$ \\
\hline $\begin{array}{l}\text { Elite Referenced } \\
\text { Excellence } \\
\text { (ERE) }\end{array}$ & $\begin{array}{l}\text { Participants engage with } \\
\text { sport for the purpose of } \\
\text { winning at the highest } \\
\text { possible level and generally } \\
\text { measure success by win/loss } \\
\text { ratios. }\end{array}$ & $\begin{array}{l}\text { The Box'Tag model operating at the Sydney } \\
\text { club would be much better suited to try and } \\
\text { engage with this category of sport } \\
\text { participant, particularly with its focus on } \\
\text { preparing athletes for amateur boxing } \\
\text { competition. }\end{array}$ \\
\hline
\end{tabular}

associated equipment through engagement in field trials and provision of both formal and informal feedback. Also, throughout the duration of the program some notable visitors attended sessions to see the program in action. Among these were the Chief Executive Officer (CEO) and Board members of Boxing Australia Limited, the Australian Head Coach for Boxing, a former CEO of the Australian Sports Commission, scientists from the Australian Institute of Sport, the Queensland Chief Scientist (who was also a former CEO of CSIRO, Australia's premier Government-funded research agency), a senior officer of the Queensland Academy of Sport, the Vice-Chancellor of the University of Canberra and academics from that institution, representatives of Australian sport technology companies and a former school principal who had an ongoing interest in youth education. The visits repeatedly caused program participants to verbally express some pride that the activities at their club had captured the attention of such people, but this sentiment was not recorded in the data that we analysed. It is possible that the Field R\&D Centre concept, the visits from luminaries and the availability of the automated scoring technology contributed in some way to the recorded participant perceptions that the Canberra PCYC Box'Tag program was "special" even though these factors were clearly not at the forefront of participant recollections of their experience with the program.

We recognise that the documents from which we extracted over-arching themes had limitations that may have influenced our findings. For instance, the 
fact that the Program Evaluation Form contained a specific question about the suitability of the training times obviously brought this matter to the direct attention of the respondents and increased the probability that the flexibility of the training schedule would emerge as a theme. It is noteworthy, however, that the other three themes were derived largely from questions that were not leading. It therefore seems likely that, overall, the themes that we have identified provide a good representation of the program characteristics that the participants most valued.

Interestingly, when participants were invited to be critical of the program by responding to Question 6 (Are there any aspects of the program that you think could have been improved, changed or deleted?), there were only four comments that could be construed as being in any way negative. Two female participants aged 16 and 17 yrs suggested that the cool-down component at the end of training sessions could possibly have been more structured, while one female aged 28 yrs and one male aged 16 yrs noted that the popularity of the program sometimes resulted in a lack of floor space and suggested that a larger training area would have enhanced their experience. On the other hand, $89 \%$ of the study sample responded to the question either by indicating that it was "not applicable" ( 3 males and 5 females aged 12 - 55 yrs) or taking the opportunity to supplement and reinforce the positive answers that they had provided to other questions (with 13 females and 13 males aged 14 - 60 yrs adopting the latter approach). This confirms that the program was highly valued by the participants, and provides further confidence that the themes identified through our analysis are truly reflective of the participants' recalled experience of the Canberra PCYC Box'Tag program.

\section{Conclusion}

We have demonstrated that a community-focused modified boxing program can achieve substantial participation and adherence, while also reaching beyond the traditional boxing demographic. The structure, primary focus and philosophical underpinnings of the program appear to have been critical to its popularity. The inclusion of elements that required participants to learn increasingly complex skills added to the attraction of the program and differentiated it from programs focused solely on use of boxing-related activities to build physical fitness. The design and deployment of various constrained games as a means for skill development contributed to participant enjoyment. A key attraction of the program was that it enabled participants to experience a strong sense of community. Diversity in the age, physical fitness and functionality of participants was seen by the participants as a major program strength, as was a general emphasis on co-operation rather than competition between program members. A notion that everyone should strive for continuous personal improvement rather than within-group superiority was broadly endorsed. The program was regarded as female-friendly and suitable for whole family involvement. Perceived equality in 
the treatment of group members was instrumental in building strong participant affection for the program. The attraction of the program can be explained within the framework of self-determination theory, with the program environment affording participants opportunities for growth in personal autonomy, competence and relatedness. The success of the modified boxing program that evolved at the Canberra PCYC suggests that there may be merit in introducing similar programs elsewhere, perhaps complementing the original Box'Tag concept. Although our research has been carried out within the context of modified boxing, the findings are clearly applicable to other sport and physical activity domains.

\section{Acknowledgements}

The authors are grateful to the Canberra Police Community Youth Club (Canberra, Australia) for hosting the program that forms the basis of this paper and for making participant feedback available for analysis. They also wish to thank the participants in the program for their commitment over its duration, and for the support and friendship that they gave to the first author of this paper in his role as program coach and to both authors in their role as researchers. Professor Keith Lyons, Dr Richard Keegan and Dr Christopher Barnes of the University of Canberra assisted the study through regular provision of much-appreciated advice.

\section{Conflicts of Interest}

The authors declare no conflicts of interest regarding the publication of this paper.

\section{References}

[1] Hahn, A. (2007) Box'Tag: A Modified Form of Boxing Competition Aimed at Improving Community Fitness and Health. Sport Health, 25, 6-8.

[2] Hahn, A., Helmer, R., Mackintosh, C., Staynes, L. and Blanchonette, I. (2011) Technological Foundations and Current Status of a Modified, Low-Risk Form of Competitive Boxing (Box’Tag). Sports Technology, 4, 178-184. https://doi.org/10.1080/19346182.2012.725413

[3] Pearn, J. (1998) Boxing, Youth and Children. Journal of Paediatrics and Child Health, 34, 311-313. https://doi.org/10.1046/j.1440-1754.1998.00231.x

[4] Pearn, J. (2000) Boxing, Brains and Balls. Medicine Today, 1, 146-148.

[5] American Academy of Pediatrics. (2011) Policy Statement-Boxing Participation by Children and Adolescents. Pediatrics, 128, 617-623. https://doi.org/10.1542/peds.2011-1165

[6] World Medical Assembly. (2005) WMA Statement on Boxing.

[7] Beran, R. and Beran, J. (2009) The Law(s) of the Rings: Boxing and the Law. Journal of Law and Medicine, 16, 684-695.

[8] Davis, P. (1993-1994) Ethical Issues in Boxing. Journal of the Philosophy of Sport, 20-21, 48-63. https://doi.org/10.1080/00948705.1993.9714503

[9] Perkins, P., Helmer, R.J.N., Mackintosh, C. and Hahn, A.G. (2017) Reflections on 
Long-Term Development and Use of Automated Scoring Technology in a Sport (Modified Boxing) Context. World Journal of Engineering and Technology, 5, 455-480. https://doi.org/10.4236/wjet.2017.53040

[10] Helmer, R., Hahn, A., Staynes, L., Denning, R., Krajewski, A. and Blanchonette, I. (2010) Design and Development of Interactive Textiles for Impact Detection and Use with an Automated Boxing Scoring System. Procedia Engineering, 2, 3065-3070.

https://doi.org/10.1016/j.proeng.2010.04.112

[11] Hahn, A., Helmer, R., Kelly, T., Partridge, K., Krajewski, A., Blanchonette, I., Barker, J., Bruch, H., Brydon, M., Hooke, N. and Andreass, B. (2010) Development of an Automated Scoring System for Amateur Boxing. Procedia Engineering, 2, 3095-3101. https://doi.org/10.1016/j.proeng.2010.04.117

[12] Krauss, S.E. (2005) Research Paradigms and Meaning Making: A Primer. The Qualitative Report, 10, 758-770.

[13] Bloor, M. and Macintosh, J. (1990) Surveillance and Concealment: A Comparison of Client Resistance in Therapeutic Communities and Health Visiting. In: Cunningham-Burley, S. and McKeganey, N.P., Eds., Readings in Medical Sociology, Routledge, London.

[14] Mclaughlin, E. and Ritchie, J. (1994) Legacies of Caring: The Experiences and Circumstances of Ex-Carers. Health and Social Care in the Community, 2, 241-253. https://doi.org/10.1111/j.1365-2524.1994.tb00170.x

[15] Kirschbaum, M.S. and Knafl, K.A. (1996) Major Themes in Parent-Provider Relationships: A Comparison of Life-Threatening and Chronic Illness Experiences'. Journal of Family Nursing, 2, 195-216. https://doi.org/10.1177/107484079600200206

[16] Hinds, P.S., Vogel, R.J. and Clarke-Steffen, L. (1997) The Possibilities and Pitfalls of Doing a Secondary Analysis of a Qualitative Data Set. Qualitative Health Research, 7, 408-424. https://doi.org/10.1177/104973239700700306

[17] Sandelowski, M. (1997) To Be of Use: Enhancing the Utility of Qualitative Research. Nursing Outlook, 45, 125-132. https://doi.org/10.1016/S0029-6554(97)90043-9

[18] Szabo, V. and Strang, V.R. (1997) Secondary Analysis of Qualitative Data. Advances in Nursing Science, 20, 66-74. https://doi.org/10.1097/00012272-199712000-00008

[19] Thorne, S. (1990) Secondary Analysis in Qualitative Research: Issues and Implications. Critical Issues in Qualitative Research Methods. Sage, London.

[20] Fielding, N. (2004) Getting the Most from Archived Qualitative Data: Epistemological, Practical and Professional Obstacles. International Journal of Social Research Methodology, 7, 97-104. https://doi.org/10.1080/13645570310001640699

[21] Law, M. (2005) Reduce, Reuse, Recycle: Issues in the Secondary Use of Research Data. IASSIST Quarterly, 29, 5-10. https://doi.org/10.29173/iq599

[22] Silva, E.R. (2007) What's [Yet] to Be Seen? Re-Using Qualitative Data. Sociological Research Online, 12, 1-12. https://doi.org/10.5153/sro.1478

[23] Moore, N. (2007) Using Qualitative Data? Sociological Research Online, 12, 1-13. https://doi.org/10.5153/sro.1496

[24] British Sociological Association (2002) Statement of Ethical Practice for the British Sociological Association. England.

[25] Whittemore, R., Chase, S.K. and Mandle, C.L. (2001) Validity in Qualitative Research. Qualitative Health Research, 11, 522-537. https://doi.org/10.1177/104973201129119299

[26] Packer, M.J. and Goicoechea, J. (2000) Sociocultural and Constructivist Theories of Learning: Ontology, Not Just Epistemology. Educational Psychologist, 35, 227-241. 
https://doi.org/10.1207/S15326985EP3504_02

[27] Polkinghorne, D.E. (1989) Phenomenological Research Methods. In: Valle, R.S. and Halling, S., Eds., Existential-Phenomenological Perspectives in Psychology, Oxford University Press, New York, 41-60. https://doi.org/10.1007/978-1-4615-6989-3_3

[28] Braun, V. and Clarke, V. (2006) Using Thematic Analysis in Psychology. Qualitative Research in Psychology, 3, 77-101. https://doi.org/10.1191/1478088706qp063oa

[29] Fielden, A.L., Sillence, E. and Little, L. (2011) Children's Understandings' of Obesity: A Thematic Analysis. International Journal of Qualitative Studies in Health and Well-Being, 6, 1-14. https://doi.org/10.3402/qhw.v6i3.7170

[30] Perkins, P. and Hahn, A. (2018) The ModBox Information Guide: A Reference Tool to Assist with the Planning, Implementation and Delivery of Community-Focused Modified Boxing Programs. ISSUU Digital Publishing Platform.

https://issuu.com/modbox8/docs/the_modbox_information_guide_

[31] Perkins, P., Jamieson, A., Spratford, W. and Hahn, A. (2018) Evaluation of Ability of Two Different Pneumatic Boxing Gloves to Reduce Delivered Impact Forces and Improve Safety. World Journal of Engineering and Technology, 6, 457-491. https://doi.org/10.4236/wjet.2018.62028

[32] Casey, M.M., Eime, R.M., Harvey, J.T., Sawyer, N.A., Craike, M.J., Symons, C.M. and Payne, W.R. (2017) The Influence of a Healthy Welcoming Environment on Participation in Club Sport by Adolescent Girls: A Longitudinal Study. BMC Sports Science, Medicine and Rehabilitation, 9, 12. https://doi.org/10.1186/s13102-017-0076-y

[33] Wanless, S.B. (2016) The Role of Psychological Safety in Human Development. Research in Human Development, 13, 6-14. https://doi.org/10.1080/15427609.2016.1141283

[34] Edmondson, A.C. and Lei, Z. (2014) Psychological Safety: The History, Renaissance, and Future of an Inter-Personal Construct. Annual Review of Organizational Psychology and Organizational Behavior, 1, 23-43. https://doi.org/10.1146/annurev-orgpsych-031413-091305

[35] Merritt, E.G., Wanless, S.B., Rimm-Kaufman, S.E., Cameron, C. and Peugh, J.L. (2012) The Contribution of Teachers' Emotional Support to Children's Social Behaviors and Self-Regulatory Skills in First Grade. School Psychology Review, 41, 141-159.

[36] Holley, L.C. and Steiner, S. (2005) Safe Space: Student Perspectives on Classroom Environment. Journal of Social Work Education, 41, 49-64. https://doi.org/10.5175/JSWE.2005.200300343

[37] Puddifoot, J.E. (1994) Community Identity and Sense of Belonging in a Northeastern English Town. The Journal of Social Psychology, 134, 601-608. https://doi.org/10.1080/00224545.1994.9922990

[38] Bollen, K.A. and Hoyle, R.H. (1990) Perceived Cohesion: A Conceptual and Empirical Examination. Social Forces, 69, 479-504. https://doi.org/10.1093/sf/69.2.479

[39] Mcmillian, D.W. and Chavis, D.M. (1986) Sense of Community: A Definition and Theory. Journal of Community Psychology, 14, 6-23. https://doi.org/10.1002/1520-6629(198601)14:1<6::AID-JCOP2290140103>3.0.CO;2 -I

[40] Warner, S., Shapiro, S., Dixon, M.A., Ridinger, L.L. and Harrison, S. (2011) The Football Factor: Shaping Community on Campus. Journal of Issues in Intercollegiate Athletics, 4, 236-256. 
[41] Kelly, D.D. and Dixon, M.A. (2011) Becoming a "Real University": The Strategic Benefits of Adding Football for NCAA Division I Institutions. Journal of Intercollegiate Sport, 2, 283-303. https://doi.org/10.1123/jis.4.2.283

[42] Swyers, H. (2010) Wrigley Regulars: Finding Community in the Bleachers? University of Illinois Press, Champaign.

[43] lopton, A.W. (2007) Predicting a Sense of Community amongst Students from the Presence of Intercollegiate Athletics: What Roles Do Gender and BCS-Affiliation Play in the Relationship? The SMART Journal, 4, 95-110.

[44] Warner, S. and Dixon, M.A. (2013) Sport and Community on Campus: Constructing a Sport Experience That Matters. Journal of College Student Development, 54, 283-298. https://doi.org/10.1353/csd.2013.0044

[45] Warner, S., Dixon, M.A. and Chalip, L.C. (2012) The Impact of Formal versus Informal Sport: Mapping the Differences in Sense of Community. Journal of Community Psychology, 40, 983-1003. https://doi.org/10.1002/jcop.21506

[46] AusPlay Participation Data for the Sport Sector: Summary of Key National Findings October 2015 to September 2016, Australian Sport Commission.

http://static.ausport.gov.au/ausplay/?page $=1$

[47] Australian Sports Commission and Gfk Moon, Market Segmentations-Adults. https://www.clearinghouseforsport.gov.au/_data/assets/pdf_file/0005/553766/1406 6_ASC_Market_Segmentation_Adults_FA_WEB.pdf

[48] Perkins, P., Hahn, A., Keegan, R. and Collis, I. (2014) Why Do Community-Based Athletes Choose to Participate in a Modified, Low-Risk form of Boxing? An Interpretative Phenomenological Analysis. Quest Journal of Research in Humanities and Social Science, 2, 60-69. https://doi.org/10.9790/9467-2116069

[49] Bernick, C. and Banks, S. (2013) What Boxing Tells Us about Repetitive Head Trauma and the Brain. Alzheimer's Research \& Therapy, 5, 23.

[50] Neselius, S., Zetterberg, H., Blennow, K., Marcusson, J. and Brisby, H. (2013) Increased CSF Levels of Phosphorylated Neurofilament Heavy Protein Following Bout in Amateur Boxers. PLoS ONE, 8, e81249. https://doi.org/10.1371/journal.pone.0081249

[51] Shirani, G.M., Mhk, M., Ashuri, A. and Eshkevari, P. (2010) Prevalence and Patterns of Combat Sport Related Maxillofacial Injuries. Journal of Emergency, Trauma and Shock, 3, 314-317. https://doi.org/10.4103/0974-2700.70744

[52] Tanriverdi, F., De Bellis, A., Battaglia, M., Bellastella, G., Bizzarro, A., Sinisi, A., Bellastella, A., Unluhizarci, K., Selcuklu, A., Casanueva, F. and Kelestimur, F. (2010) Investigation of Antihypothalamus and Antipituitary Antibodies in Amateur Boxers: Is Chronic Repetitive Head Trauma-Induced Pituitary Dysfunction Associated with Autoimmunity? European Journal of Endocrinology, 162, 861-867. https://doi.org/10.1530/EJE-09-1024

[53] Kochno, T. (2011) Boxing Injuries, in Enyclopedia of Sports Medicine. Sage Publications, Thousand Oaks, CA.

[54] Potter, M.R., Snyder, A.J. and Smith, G.A. (2011) Boxing Injuries Presenting to US Emergency Departments, 1990-2008. American Journal of Preventive Medicine, 40, 462-467. https://doi.org/10.1016/j.amepre.2010.12.018

[55] Oelman, B.J., Rose, C.M.E. and Arlow, K.J. (1983) Boxing Injuries in the Army. Journal of the Royal Army Medical Corps, 129, 32-37. https://doi.org/10.1136/jramc-129-01-10

[56] Kaste, M., Kuurne, T., Vilkki, J., Katevuo, K., Sainio, K. and Meurala, H. (1982) Is 
Chronic Brain Damage in Boxing a Hazard of the Past? The Lancet, 320, 1186-1188. https://doi.org/10.1016/S0140-6736(82)91203-X

[57] Haglund, Y. and Perrson, H.E. (1990) Does Swedish Amateur Boxing Lead to Chronic Brain Damage? A Retrospective Clinical Neurophysiological Study. Acta Neurologica Scandinavica, 82, 353-360. https://doi.org/10.1111/j.1600-0404.1990.tb03316.x

[58] Casson, I.R., Siegel, O., Sham, R., Campbell, E.A., Tarlau, M. and Didomenico, A. (1984) Does Swedish Amateur Boxing Lead to Chronic Brain Damage? A Retrospective Clinical Neurophysiological Study. JAMA, 251, 2663-2667. https://doi.org/10.1001/jama.1984.03340440021020

[59] Mclatchie, G., Brooks, N., Galbraith, S., Hutchison, J.S.F., Wilson, L. and Melville, I. (1987) Clinical Neurological Examination, Neuropsychology, Electroencephalography and Computed Tomographic Head Scanning in Active Amateur Boxers. Journal of Neurology \& Psychiatry, 50, 96-99. https://doi.org/10.1136/jnnp.50.1.96

[60] Bailey, D., Jones, D., Sinnott, A., Brugniaux, J., New, K., Hodson, D., Marley, C., Smirl, J., Ogoh, S. and Ainslie, P. (2013) Impaired Cerebral Haemodynamic Function Associated with Chronic Traumatic Brain Injury in Professional Boxers. Clinical Science, 124, 177-189. https://doi.org/10.1042/CS20120259

[61] Lundberg, G.D. (1993) Medical Arguments for Nonparticipation in Boxing. In: Bd, J., Ed., Medical Aspects of Boxing, CRC Press, Boca Raton, FL, 11-15.

[62] Zhang, L., Heier, L.A., Zimmerman, R.D., Jordan, B. and Meghs, U.A. (2006) Diffusion Anisotropy Changes in the Brains of Professional Boxers. American Journal of Neuroradiology, 27, 2000-2004.

[63] Pineda, P. and Gould, D. (2010) The Neuroanatomical Relationship of Dementia Pugilistica and Alzheimer's Disease. Neuroanatomy, 9, 5-7.

[64] Cabanis, E., Iba-Zizen, M., Perez, G., Senegas, X., Furgoni, J., Pineau, J., Louquet, J. and Henrion, R. (2010) Boxing: Traumatology and Prevention. Bulletin de P Academie Nationale de Medecine, 194, 1219-1236.

[65] Svinth, J. (2007) Death under the Spotlight: Analyzing the Data. Journal of Combative Sport, 1-19.

[66] Smillie, M. (2003) There Is No Sport Like Boxing. British Columbia Medical Journal, 45, 473-474.

[67] Stinson, S. (2012) Boxing Welcomes All the Health Risks. https://nationalpost.com/sports/boxing-welcomes-all-the-health-risks

[68] Scanlan, T.K. and Simons, J.P. (1982) The Construct of Sport Enjoyment. In: Roberts, G.C., Ed., Motivation in Sport and Exercise, Human Kinetics, Champaign, 199-215.

[69] Brustad, R.J. (1988) Affective Outcomes in Competitive Youth Sport: The Influence of Intrapersonal and Socialization Factors. Journal of Sport and Exercise Psycholo$g y$, 10, 307-321. https://doi.org/10.1123/jsep.10.3.307

[70] Scanlan, T.K., Carpenter, P.J., Lobel, M. and Simons, J.P. (1993) Sources of Enjoyment for Youth Sport Activities. Pediatric Exercise Science, 5, 275-285. https://doi.org/10.1123/pes.5.3.275

[71] Mandigo, J.L. and Couture, R.T. (1996) An Overview of Components of Fun in Physical Education, Organised Sport and Physical Activity Programs. Avante, 2, 56-72.

[72] Csikszentmihalyi, M. (1990) Flow: The Psychology of Optimal Experience. Harper 
\& Row, New York.

[73] Chalip, L.M., Csikszentmihalyi, M., Kleiber, D. and Larson, R. (1984) Variations of Experience in Formal and Informal Sport. Research Quarterly for Exercise and Sport, 55, 109-116. https://doi.org/10.1080/02701367.1984.10608385

[74] Wankel, L.M. and Sefton, J.M.M. (1989) Factors Distinguishing High- and Low-Fun Experiences in Ice Hockey. World Leisure and Recreation, 31, 29-31.

[75] Renshaw, I., Chow, J., Davids, K. and Hammond, J. (2010) A Constraints-Led Perspective to Understanding Skill Acquisition and Game Play: A Basis for Integration of Motor Learning Theory and Physical Education Praxis. Physical Education and Sports Pedagogy, 2, 60-69. https://doi.org/10.1080/17408980902791586

[76] Chow, J.Y., Davids, K., Button, C., Shuttleworth, R., Renshaw, I. and AraúJo, D. (2006) Nonlinear Pedagogy: A Constraints-Led Framework to Understanding Emergence of Game Play and Skills. Nonlinear Dynamics, Psychology, and Life Sciences, 10, 71-103.

[77] Pill, S. (2012) Teaching Game Sense in Soccer. Journal of Physical Education, Recreation \& Dance, 83, 42-52. https://doi.org/10.1080/07303084.2012.10598746

[78] Light, R. and Georgakis, S. (2005) Integrating Theory and Practice in Teacher Education: The Impact of a Game Sense Unit of Female Pre-Service Primary Teachers. Journal of Physical Education New Zealand, 38, 67-80.

[79] Werner, P., Thorpe, R. and Bunker, D. (1996) Teaching Games for Understanding: Evolution of a Model. The Journal of Physical Education Recreation and Dance, 67, 28-33. https://doi.org/10.1080/07303084.1996.10607176

[80] Pill, S. (2008) Play with Purpose: Teaching Games for Understanding. Active and Healthy, 15, 7-10.

[81] Light, R., Curry, C. and Mooney, A. (2014) Game Sense as a Model for Delivering Quality Teaching in Physical Education. Asia-Pacific Journal of Health, Sport and Physical Education, 5, 67-81. https://doi.org/10.1080/18377122.2014.868291

[82] Strean, W.B. (1997) Ideology Critique: Improving Instruction by Thinking about Your Thinking. Journal of Physical Education, Recreation, and Dance, 68, 53-56. https://doi.org/10.1080/07303084.1997.10604928

[83] Schmidt, R.A. and Lee, T.D. (2005) Motor Control and Learning: A Behavioral Emphasis. Human Kinetics, Champaign.

[84] Shultz, S.P., Stoner, L., Lambrick, D.M. and Lane, A.M. (2014) A Boxing-Oriented Exercise Intervention for Obese Adolescent Males: Findings from a Pilot Study. Journal of Sports Science and Medicine, 13, 751-757.

[85] Arseneau, E., Mekary, S. and Leger, L.A. (2011) Vo2 Requirements of Boxing Exercises. The Journal of Strength \& Conditioning Research, 25, 348-359. https://doi.org/10.1519/JSC.0b013e3181ef64cb

[86] Joussellin, E., Handschuh, R., Barrault, D. and Rieu, M. (1984) Maximal Aerobic Power of French Top Level Competitors. Journal of Sports Medicine and Physical Fitness, 24, 175-182.

[87] Friedmann, B., Jost, J., Rating, T., Weller, E., Werle, E., Eckardt, K.-U., Bärtsch, P. and Mairbäurl, H. (1999) Effects of Iron Supplementation on Total Body Haemoglobin during Endurance Training at Moderate Altitude. International Journal of Sports Medicine, 20, 78-85. https://doi.org/10.1055/s-2007-971097

[88] Smith, M. (2006) Physiological Profile of Senior and Junior England International Amateur Boxers. Journal of Sports Science and Medicine, 5, 74-89.

[89] Bellinger, B., St Clair Gibson, A., Oelofse, A., Oelofs, R. and Lambert, M. (1997) 
Energy Expenditure of a Noncontact Boxing Training Session Compared with Submaximal Treadmill Running. Medicine \& Science in Sports \& Exercise, 29, 1653-1656. https://doi.org/10.1097/00005768-199712000-00016

[90] Coalter, F. (2010) The Politics of Sport-For-Development: Limited Focus Programmes and Broad Gauge Problems? International Review for the Sociology of Sport, 45, 295-314. https://doi.org/10.1177/1012690210366791

[91] Doty, J. (2006) Sports Build Character?! Journal of College and Character, 7, 1-9. https://doi.org/10.2202/1940-1639.1529

[92] Omar-Fauzee, M., Nazarudin, M., Saputra, Y., Sutresna, N., Taweesuk, D., Chansem, W., Rozita Latif, R. and Geok, S. (2012) The Strategies for Character Building through Sports Participation. International Journal of Academic Research in Business and Social Sciences, 2, 48-58.

[93] Eccles, J.S. and Gootman, J.A. (2002) Features of Positive Developmental Settings. In: Eccles, J.S. and Gootman, J.A., Eds., Community Programs to Promote Youth Development, National Academy Press, Washington DC, 86-118.

[94] Hagger, M. and Chatzisarantis, N. (2008) Self-Determination Theory and the Psychology of Exercise. International Review of Sport and Exercise Psychology, 1, 79-103. https://doi.org/10.1080/17509840701827437

[95] Deci, E.L. and Ryan, R.M. (1985) Intrinsic Motivation and Self-Determination in Human Behavior. Plenum, New York. https://doi.org/10.1007/978-1-4899-2271-7

[96] Ryan, R., Williams, G., Patrick, H. and Deci, E. (2009) Self-Determination Theory and Physical Activity: The Dynamics of Motivation in Development and Wellness. Hellenic Journal of Psychology, 6, 107-124.

[97] Ryan, R. and Deci, E. (2002) Overview of Self-Determination Theory: An Organismic-Dialectical Perspective. Rochester University Press, Rochester.

[98] Wilson, P., Rogers, W., Rodgers, W. and Wild, T. (2006) The Psychological Need Satisfaction in Exercise Scale. Journal of Sport and Exercise Psychology, 28, 231-251. https://doi.org/10.1123/jsep.28.3.231

[99] Markland, D. (2009) The Mediating Role of Behavioural Regulations in the Relationship between Perceived Body Size Discrepancies and Physical Activity among Adult Women. Hellenic Journal of Psychology, 6, 169-182.

[100] Deci, E. and Ryan, R. (2000) The "What" and "Why" of Goal Pursuits: Human Needs and the Self-Determination of Behavior. Psychological Inquiry, 11, 227-268. https://doi.org/10.1207/S15327965PLI1104_01

[101] Ryan, R. and Deci, E. (2000) Self-Determination Theory and the Facilitation of Intrinsic Motivation, Social Development, and Well-Being. American Psychologist, 55, 68-78. https://doi.org/10.1037/0003-066X.55.1.68

[102] Linke, S., Gallo, L. and Norman, G. (2011) Attrition and Adherence Rates of Sustained vs. Intermittent Exercise Interventions. Annals of Behavioral Medicine, 42, 197-209. https://doi.org/10.1007/s12160-011-9279-8

[103] Nam, S., Dobrosielski, D.A. and Stewart, K.J. (2012) Predictors of Exercise Intervention Dropout in Sedentary Individuals with Type 2 Diabetes. Journal of Cardiopulmonary Rehabilitation and Prevention, 32, 370-378. https://doi.org/10.1097/HCR.0b013e31826be485

[104] Lockwood, P. and Perlman, D.J. (2008) Enhancing the Youth Sport Experience: A Re-Examination of Methods, Coaching Style, and Motivational Climate. The Journal of Youth Sports: Youth First, 4, 30-34.

[105] Perkins, P., Hahn, A., Lucas, R. and Keegan, R. (2014) The Boxing Conundrum: Is 
There a Place for a New Variant of the Sport? Quest Journal of Research in Humanities and Social Science, 2, 9-25.

[106] Bailey, R., Collins, D., Ford, P., Álne Macnamara, A., Toms, M. and Pearce, G. (2010) Participant Development in Sport: An Academic Review. Sports Coach UK and Sport Northern Ireland, 106.

[107] Collins, M. (1995) Sport Development Locally and Regionally. Institute and Amenity Management, Reading.

[108] Perkins, P. and Hahn, A. (2018) Update and Current Status of a Sport-Based Development Initiative (ModBox). ISSUU Digital Publishing Platform.

https://issuu.com/modbox8/docs/update_and_current_status 